\section{Lasting Effects of COVID-19: Reimbursement Reform?}

$\mathbf{R}$ eimbursement for our services as medical oncologists has always been a difficult issue for me. Payment based on evaluation and management codes historically has required a physical visit and laborious documentation, and the payments themselves barely kept the lights on. I was always miffed that even minor surgical procedures could bring in big bucks, but an hour spent talking a patient out of an unnecessary and costly procedure might be reimbursed at a rate less than an electrician fixing faulty wiring. It never made sense to me that cognitive care was so poorly valued. Of course, this is why adult and pediatric primary care specialities and psychiatry are struggling. Those who incur a big debt going to medical school will be less likely to consider these lower-paying jobs, especially in a community-based setting, though large HMOs and facility-based practices can ease the pain a bit through various funds flow models.

Thought leaders have generally agreed that reimbursement reform is needed but have had found little consensus on how to achieve that reform. Allowing "time" to be a factor in the visit has helped, but it hasn't leveled the playing field. The Centers for Medicare \& Medicaid Services (CMS) led the way, and some but not all insurers have followed suit. Then a pandemic happened.

In a heartbeat (or so it seemed), CMS introduced flexibilities for provider and patient safety through the CARES Act. ${ }^{1}$ Virtually every type of visit that does not absolutely require physical presence is allowable and reimbursable as a video visit or even a telephone call. Even email correspondence, through protected portals, is reimbursable. And the time spent reviewing records is now reimbursable. We can even "cross" state lines to treat patients who live in states in which we are not licensed.

To be fair, we don't yet know how this will play out in the long run financially, but so far I am cautiously optimistic. Ultimately, my point is that this miserable pandemic has made us examine how we provide care, and assess what is necessary and what is not. And CMS is providing payment for real work that previously was unbillable.

Virtually every opinion leader has agreed that telehealth and other remote activities such as monitoring are here to stay, though perhaps not with the current frequency. Patients like the convenience and the visits seem to take less time, allowing physicians to have higher capacity. As long as physicians are reimbursed properly, who would argue against it? Although the CARES Act theoretically will be repealed when the pandemic ends, I suspect elements that improve healthcare delivery, like telehealth payments, will remain.

Whoever thought a tiny strand of RNA could improve our healthcare system?

\section{Reference}

1. CARES Act, HR 748, 116th Congress (2019-2020). Pub L No. 116-136. Accessed October 8, 2020. Available at: https://www.congress.gov/bill/116th-congress/senate-bill/3548/text?q=product+actualizaci\%C3\%B3n JNCCN@nccn.org or log into www.editorialmanager.com/JNCCN.

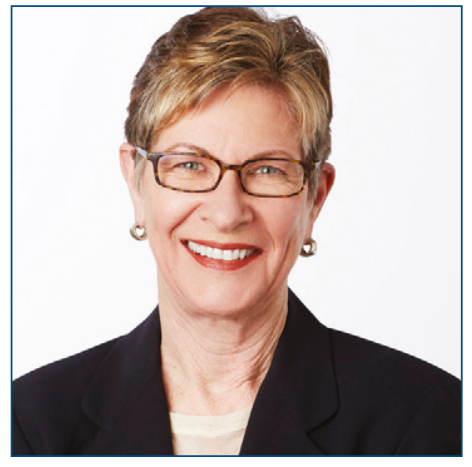

MARGARET TEMPERO, MD

Margaret Tempero, MD, is a Professor of Medicine and Director of the UCSF Pancreas Center and editor-in-chief of JNCCN. Her research career has focused on pancreatic ductal adenocarcinoma, especially in the area of investigational therapeutics. Dr. Tempero has served on the ASCO Board of Directors and as ASCO President. She currently serves on the ASCO Conquer Cancer Foundation Board. She codirected the AACR/ASCO Methods in Clinical Cancer Research and taught this course and similar courses in Europe and Australia. She was founding Chair of the $\mathrm{NCl}$ Clinical Oncology Study Section and served as a member and Chair of the $\mathrm{NCl}$ Board of Scientific Counselors Subcommittee A. She is a member of the Scientific Steering Committee and Chair of the Clinical and Translational Study Section for the Cancer Prevention \& Research Institute of Texas. She is or has been on the Scientific Advisory Boards of the Lustgarten Foundation, the Pancreatic Cancer Action Network, the V Foundation, The Alberta Canada Cancer Board, and the EORTC. She served as a member of the Oncology Drug Advisory Committee for the FDA. She has served as Deputy Director and Interim Director for the UNMC Eppley Cancer Center. She is Chief Emeritus of the Division of Medical Oncology at UCSF. She served as the founding Deputy Director and was later Director of Research Programs at the UCSF Helen Diller Family Comprehensive Cancer Center.

doi: $10.6004 /$ jnccn.2020.0054

The ideas and viewpoints expressed in this editorial are those of the author and do not necessarily represent any policy, position, or program of NCCN. 